\title{
Use of the PiCCO system in critically ill patients with septic shock and acute respiratory distress syndrome: a study protocol for a randomized controlled trial
}

\author{
Zhongheng Zhang ${ }^{1 *}$, Xiao Xu' ${ }^{1}$ Min $\mathrm{YaO}^{2}$, Huilan $\mathrm{Chen}^{3}$, Hongying $\mathrm{Ni}^{1}$ and Haozhe Fan ${ }^{1}$
}

\begin{abstract}
Background: Hemodynamic monitoring is very important in critically ill patients with shock or acute respiratory distress syndrome(ARDS). The PiCCO (Pulse index Contour Continuous Cardiac Output, Pulsion Medical Systems, Germany) system has been developed and used in critical care settings for several years. However, its impact on clinical outcomes remains unknown.

Methods/design: The study is a randomized controlled multi-center trial. A total of 708 patients with ARDS, septic shock or both will be included from January 2012 to January 2014. Subjects will be randomized to receive PiCCO monitoring or not. Our primary end point is 30-day mortality, and secondary outcome measures include ICU length of stay, days on mechanical ventilation, days of vasoactive agent support, ICU-free survival days during a 30-day period, mechanical-ventilation-free survival days during a 30-day period, and maximum SOFA score during the first 7 days.
\end{abstract}

Discussion: We investigate whether the use of PiCCO monitoring will improve patient outcomes in critically ill patients with ARDS or septic shock. This will provide additional data on hemodynamic monitoring and help clinicians to make decisions on the use of PiCCO.

Trial registration: www.clinicaltrials.gov NCT01526382

Keywords: Pulse index Contour Continuous Cardiac Output, Shock, Acute respiratory distress syndrome, Mortality

\section{Background}

Hemodynamic monitoring and the associated fluid therapy are of critical importance in the management of critically ill patients. The optimization of fluid status remains a challenge in critical care settings because fluid overload will lead to organ edema and an ensuing increase in mortality [1,2], whereas inadequate circulating volume will result in insufficient perfusion pressure and oxygen delivery. Therefore, monitoring the fluid status of critically ill patients is very important. Recent decades have witnessed rapid advances in fluid monitoring techniques. Pulmonary artery catheters have been

\footnotetext{
* Correspondence: zh_zhang1984@hotmail.com

'Department of Critical Care Medicine, Jinhua Municipal Central Hospital, 351 Mingyue Street, Jinhua City, Zhejiang 3210002, PR China

Full list of author information is available at the end of the article
}

widely used for more than five decades, but unfortunately their usefulness in improving patient outcomes seems disappointing [3]. The PiCCO system (Pulse index Contour Continuous Cardiac Output, Pulsion Medical Systems, Germany) incorporates a transpulmonary thermodilution technique (TPTD) and continuous pulse contour analysis. It is a minimally invasive technique, which gives beat-by-beat monitoring of cardiac output, and can provide accurate information on volume status and pulmonary edema. Furthermore, the PiCCO monitor is an 'all-inclusive' device, which provides a full picture of a patient's hemodynamic status, including vascular tone, preload, and cardiac function [4]. However, clinical studies investigating the usefulness of the PiCCO system have mainly focused on intermediate physiological parameters, such as fluid responsiveness, oxygenation and 
pulmonary edema, [5,6], and only a few studies have investigated clinical outcomes of patients managed using a PiCCO monitor $[7,8]$. Although these studies have promising results, the link between its use and clinical outcomes (for example mortality, length of stay in an ICU, duration of mechanical ventilation) is largely unknown.

Patients with acute respiratory distress syndrome (ARDS) are characterized by increased pulmonary extravascular lung water (EVLW), and may potentially benefit from EVLW monitoring. Simmons et al. [9] noticed that a more negative fluid balance in ARDS patients was associated with improved survival. More recently, numerous studies have demonstrated that elevated EVLW is associated with an increased mortality rate $[10,11]$. A recent meta-analysis by our group also supports this notion [12]. Thus, management algorithms aiming to optimize the extravascular lung water index (EVLWI) are assumed to be beneficial to this group of patients. The other disease entity that is commonly encountered in ICUs is septic shock. This group of patients usually receives infusions of large amounts of fluid during theinitial period to maintain an adequate perfusion pressure. Early goal-directed therapy (EGDT), as proposed by Rivers, is a clinically useful bundle to guide fluid therapy [13]. However, it is not without criticism and the definition of appropriate fluid treatment is still open to debate for this group of patients $[14,15]$.

In this randomized controlled trial, we aim to assess whether the management algorithm using data obtained with a PiCCO system can improve clinical outcomes in critically ill patients with septic shock or ARDS. We hypothesize that a management algorithm based on the PiCCO system will benefit critically ill patients in terms of mortality, length of stay in an ICU and ventilationfree days.

\section{Methods}

The study is designed as a prospective randomized controlled multi-center trial in the ICUs of four tertiary academic centers. These are mixed ICUs treating both surgical and medical patients. The total number of beds is 96 . The study will last for a period of 2 years. The end of the study is defined by the last follow-up of the last enrolled patient. The study was approved by the ethics committees of the participating institutions.

\section{Patient selection}

All patients admitted to a participating ICU during the study period will be assessed for potential eligibility. Patients with septic shock, ARDS or both are considered to be eligible. Sepsis is defined as infection plus systemic inflammatory response syndrome (SIRS). General variables are: (1) fever $\left(>38.3^{\circ} \mathrm{C}\right)$ or hypothermia (core temperature $<36^{\circ} \mathrm{C}$ ); (2) heart rate $>90 \mathrm{~min}^{-1}$ or $>2 \mathrm{SD}$ above the normal value for age; (3) tachypnea; (4) altered mental state; (5) significant edema or positive fluid balance (>20 ml. $\mathrm{kg}^{-1}$ over $24 \mathrm{hrs}$ ); and (6) hyperglycemia (plasma glucose $>140 \mathrm{mg}^{-1} \mathrm{dl}^{-1}$ in the absence of diabetes). Inflammatory variables are: (1) leukocytosis (white blood cell (WBC) count $>12000 \mu \mathrm{L}^{-1}$ ) or leucopenia (WBC count $<4000 \mu \mathrm{L}^{-1}$ ); (2) normal WBC count with $>10 \%$ immature forms; (3) plasma C-reactive protein $>$ SD above upper normal limit; and (4) plasma procalcitonin $>2$ SD above upper normal limit. Septic shock is defined as a systolic blood pressure (SBP) of $<90 \mathrm{~mm} \mathrm{Hg}$ or mean arterial pressure $<70 \mathrm{~mm} \mathrm{Hg}$ or a SBP decrease $>40 \mathrm{~mm} \mathrm{Hg}$ despite adequate fluid resuscitation [16]. ARDS is defined according to the Berlin definition [17]: (1) the onset should be within one week of a known clinical insult or new/worsening respiratory symptoms; (2) chest imaging shows bilateral opacities that cannot be fully explained by effusions, lobar/lung collapse or nodules; (3) respiratory failure is not fully explained by cardiac failure or fluid overload. An objective assessment may be needed to exclude hydrostatic edema if no risk factor is present. ARDS is divided into three mutually exclusive categories of mild $\left(200<\mathrm{PaO}_{2} / \mathrm{FiO}_{2} \leq 300\right.$ with positive end-expiratory pressure (PEEP) or continuous positive airway pressure $\left.(\mathrm{CPAP}) \geq 5 \quad \mathrm{cmH}_{2} \mathrm{O}\right)$, moderate $\left(100<\mathrm{PaO}_{2} / \mathrm{FiO}_{2} \leq 200\right.$ with PEEP $\left.\geq 5 \mathrm{cmH}_{2} \mathrm{O}\right)$ and severe $\left(\mathrm{PaO}_{2} / \mathrm{FiO}_{2} \leq 100\right.$ with PEEP $\geq 5 \mathrm{cmH}_{2} \mathrm{O}$ ). The diagnosis of ARDS is made by a specialist. Chest imaging (for example a chest $\mathrm{X}$-ray or computer tomography) is interpreted by a radiologist. Patients are excluded if they met the exclusion criteria: (1) younger than 18 years; (2) experienced hemorrhagic shock; (3) are moribund, or informed consent cannot be obtained; (4) contraindications to catheter insertion, including overlying infection and arterial grafting; (5) conditions likely to render PiCCO measurements inaccurate, including intracardiac shunts, significant tricuspid regurgitation, and cooling or rewarming [18-20].

\section{Interventions \\ Experimental intervention}

The PiCCO system is used within 2 hours of enrollment. Central venous access is created for the injection of cold water and measurement of central venous pressure (CVP). The choice of type of central venous catheter $(\mathrm{CVC})$ and insertion site are at the discretion of the treating physician. The preferred insertion site is the jugular or subclavian position. We choose the femoral position only when both of these sites are contraindicated. A thermistor-tipped arterial catheter is inserted into the femoral artery. Occasionally, the axillary artery is used when femoral artery catheterization is contraindicated [21]. Then 15 to $20 \mathrm{ml}$ of normal saline at a temperature $<8^{\circ} \mathrm{C}$ is injected into the central vein, and 
various hemodynamic parameters can be obtained through analysis of variations in blood temperature taken by the temperature sensor of the arterial catheter. At least three cold boluses are required for each calibration to obtain an acceptable precision [22]. The calibration should be performed at least every 8 hours, or following a major change in a patient's clinical condition [23]. To exclude variations in blood volume and temperature caused by continuous renal replacement therapy (CRRT), the calibration will not be performed immediately after CRRT is switched on or off, and the measurement can be performed after the blood temperature reaches a steady state (after two minutes) [24,25].

Fluid management aims to optimize the effective circulating blood volume; vasoactive agents are used to achieve a mean arterial pressure of at least $60 \mathrm{mmHg}$ when the volume status is optimal and extravascular lung water is optimized to a negative fluid balance $[26,27]$. If the intrathoracic blood volume index (ITBVI) is less than $850 \mathrm{ml} \cdot \mathrm{m}^{-2}$, a $500 \mathrm{ml}$ bolus of hydroxyethyl starch 130/0.4 (Voluven ${ }^{\circledR}$ ) is infused over $30 \mathrm{~min}$ aiming for an ITBVI of 850 to $1000 \mathrm{ml} . \mathrm{m}^{-2}$. The bolus can be repeated if the target is not reached. If the ITBVI exceeds $1000 \mathrm{ml} . \mathrm{m}^{-2}$, nitroglycerin and/or dobutamine are used based on mean arterial pressure (MAP) and cardiac output (CI). If EVLWI $\geq 10 \mathrm{ml} / \mathrm{kg}$, furosemide is used. If MAP $<60 \mathrm{mmHg}$, norepinephrine is started at $0.05 \mu \mathrm{g} . \mathrm{kg}^{-1} \cdot \mathrm{min}^{-1}$ with the option to increase at an increment of $0.05 \mu \mathrm{g} \cdot \mathrm{kg}^{-1} \cdot \mathrm{min}^{-1}$. If MAP > $100 \mathrm{mmHg}$, nitroglycerin is given at the dose range of 0.5 to $3.0 \mu \mathrm{g} \cdot \mathrm{kg}^{-1} \cdot \mathrm{min}^{-1}$. A red blood cell (RBC) transfusion is triggered when the hemoglobin level $\mathrm{Hb}<7 \mathrm{~g} \cdot \mathrm{dl}^{-1}$, and if $\mathrm{CI}<2.5 \mathrm{~L} \cdot \mathrm{min}^{-1} \cdot \mathrm{m}^{-2}$ dobutamine is started at the dose of $2.5 \mu \mathrm{g} \cdot \mathrm{kg}^{-1} \cdot \mathrm{min}^{-1}$. The target is to maintain central venous oxygen saturation $\mathrm{ScvO}_{2}>70 \%$ (Figure 1). Dynamic parameters for fluid responsiveness such as pulse pressure variation and stroke volume variation were not included in the protocol due to the requirement for positive ventilation, heavy sedation or paralysis, and a regular cardiac rhythm. The PiCCO system will be removed if the patient is clinically stable for 48 hours as determined by attending physicians. This system can be maintained for a maximum of 10 days. If catheter-related bloodstream infection (CRBSI) is suspected, the central venous catheter will be removed and sent for microbiological study, and the catheter will be exchanged for a new one.

\section{Control intervention}

Patients in the control arm will not receive PiCCO monitoring, but a central venous catheter is routinely inserted. If the CVP is less than $8 \mathrm{mmHg}$, a $500 \mathrm{ml}$ bolus of hydroxyethyl starch 130/0.4 (Voluven ${ }^{\circledR}$ ) is infused over $30 \mathrm{~min}$ aiming to give a CVP of 8 to $12 \mathrm{mmHg}$. The bolus can be repeated if the target is not reached. If the CVP exceeds $12 \mathrm{mmHg}$, furosemide and/or nitroglycerin and/ or dobutamine are used at the discretion of the attending physician. If MAP is less than $60 \mathrm{mmHg}$, norepinephrine is started at $0.05 \mu \mathrm{g} \cdot \mathrm{kg}^{-1} \cdot \mathrm{min}^{-1}$ with the option to increase at an increment of $0.05 \mu \mathrm{g} \cdot \mathrm{kg}^{-1} \cdot \mathrm{min}^{-1}$. If MAP > 100 $\mathrm{mmHg}$, nitroglycerin is given at the dose range of 0.5 to $3.0 \mu \mathrm{g} . \mathrm{kg}^{-1} \cdot \mathrm{min}^{-1}$. An RBC transfusion is triggered when $\mathrm{Hb}<7$ g. $\mathrm{dl}^{-1} . \mathrm{ScvO}_{2}$ is maintained $>70 \%$ (Figure 2 ).

\section{Study end point}

The primary endpoint is 30-day mortality (death from any cause before day 30 ).

\section{Secondary outcome measures}

ICU length of stay: Since the time of ICU discharge may be affected by the availability of beds on a general ward, we predefine the ICU length of stay as the day from ICU admission to the day when the patient is ready for ICU discharge. A patient is considered ready for discharge when he or she is no longer in need for vital organ support.

Days on mechanical ventilation: The criteria for termination of mechanical ventilation: a cooperative patient, recovery from primary disease, hemodynamically stable, adequate and strong cough reflex, positive end-expiratory pressure $<5 \mathrm{cmH}_{2} \mathrm{O}$, pressure support $<10 \mathrm{cmH}_{2} \mathrm{O}$ and the spontaneous breathing trial is successfully passed.

Ventilator-free days during 30-day period.

Days of vasoactive agent support: The sum of the number of days with one or more vasoactive agents to maintain a mean arterial pressure $>60 \mathrm{mmHg}$. Vasoactive-agent-free days in 30-day period. ICU-free survival days during 30-day period. Maximum sequential organ failure assessment (SOFA) score during the first 7 days.

\section{Data safety monitoring board}

A Data Safety Monitoring Board chaired by the director of the Department of Critical Care Medicine (XX) of Jinhua Municipal Central Hospital, comprising experts in clinical trials, biostatistics and intensive care, has been established. The board will review data on patient characteristics, compliance and study outcome in an interim analysis (based on the availability of primary outcomes for 350 patients). The study will be terminated if one arm turns out to be harmful compared to the other.

Adverse events were considered to be: hematoma, pneumothorax, arterial emboli, catheter-relatedbloodstream infection, hemorrhage, pseudoaneurysm or arrhythmia. 


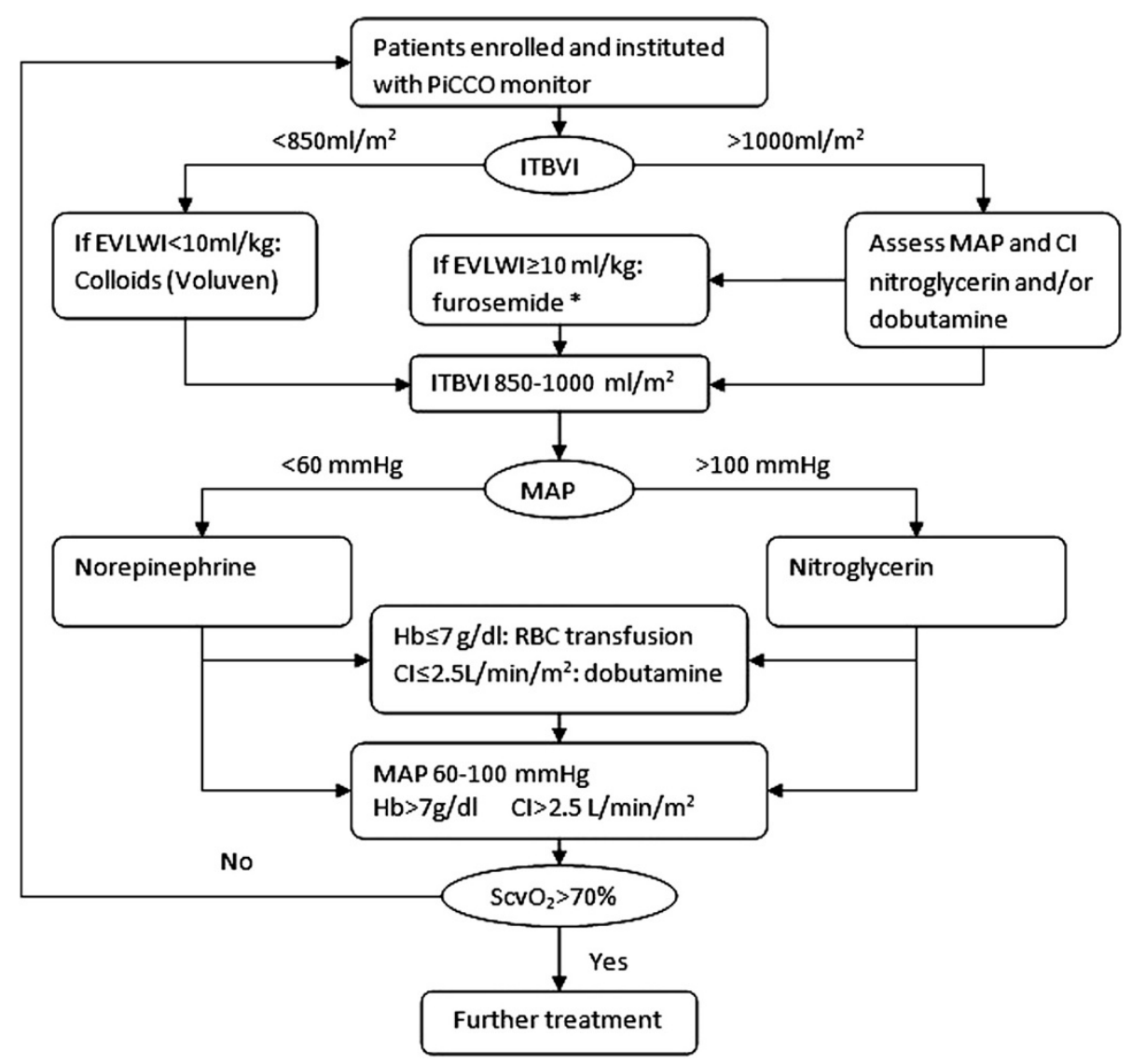

Figure 1 Algorithm for hemodynamic management according to transpulmonary thermodilution-derived data. $|\mathrm{f}| \mathrm{ITBV} \mid<850 \mathrm{ml} . \mathrm{m}^{-2}$, a $500 \mathrm{ml}$ bolus of hydroxyethyl starch 130/0.4 (Voluven ${ }^{\circledR}$ ) was infused over $30 \mathrm{~min}$ aiming at an ITBVI of 850 to $1000 \mathrm{ml} . \mathrm{m}^{-2}$. The bolus can be repeated if the target is not reached. If ITBVI $>1000 \mathrm{ml} . \mathrm{m}^{-2}$, nitroglycerin and/or dobutamine are used based on MAP and CI. If EVLWI $\geq 10 \mathrm{ml} / \mathrm{kg}$, furosemide is used. If MAP $<60 \mathrm{mmHg}$, norepinephrine is started at $0.05 \mu \mathrm{g} \cdot \mathrm{kg}^{-1}$. $\mathrm{min}^{-1}$ with the option to increase at an increment of $0.05 \mu \mathrm{g} \cdot \mathrm{kg}^{-1} \cdot \mathrm{min}^{-1}$. If MAP $>100 \mathrm{mmHg}$, nitroglycerin is given at the dose range of 0.5 to $3.0 \mu \mathrm{g} \cdot \mathrm{kg}^{-1} \cdot \mathrm{min}^{-1}$. RBC transfusion is triggered when $\mathrm{Hb}<7 \mathrm{~g} . \mathrm{dl}^{-1}$, and if $\mathrm{Cl}<2.5 \mathrm{~L} \cdot \mathrm{min}^{-1} \cdot \mathrm{m}^{-2}$ dobutamine is started at the dose of $2.5 \mu \mathrm{g} \cdot \mathrm{kg}^{-1} \cdot \mathrm{min}^{-1}$. The target is to maintain $\mathrm{ScvO}_{2}>70 \%$. Cl, cardiac output; EVLWI, extravascular lung water index; Hb, hemoglobin level; ITBVI, intrathoracic blood volume index; MAP, mean arterial pressure; RBC, red blood cell; $\mathrm{ScvO}_{2}$, central venous oxygen saturation.

\section{Sample size and statistical analysis}

We assumed that the overall mortality at 30 days is $40 \%$ $[28,29]$. A sample size was calculated to detect a $10 \%$ difference in mortality at day 30 between the two groups with a two-tailed test, a significance level of $5 \%$ and a power of $80 \%$. We plan to include a total of 708 subjects.

Baseline characteristics will be reported. The difference in 30-day mortality between the two groups will be tested using a chi-square test and intention-to-treat (ITT) analysis. Time-to-event variables including length of stay in the ICU, duration of mechanical ventilation and 30-day survival are compared between the two groups using a log-rank test. Multivariate analysis (the Cox proportional hazards regression model) is used to estimate the hazard ratio adjusted for age, severity of illness and disease category. Age and the APACHE II score will be managed as continuous variables. Adverse events will be reported according to the ITT protocol. All tests are two sided and $P<0.05$ is considered to be statistically significant. Statistical analysis will be performed using Stata 11.0 (College Station, TX 77845, USA).

\section{Randomization}

Eligible consecutive patients will be randomly assigned to one of the treatment groups using randomization sequences generated by computer and stratified according to the primary diagnostic category on admission, namely, septic shock and ARDS. Allocation concealment is achieved using sequentially numbered, sealed opaque envelopes.

\section{Blindness}

The blinding of non-pharmacological treatment in our study is complicated and costly. However, every effort is 


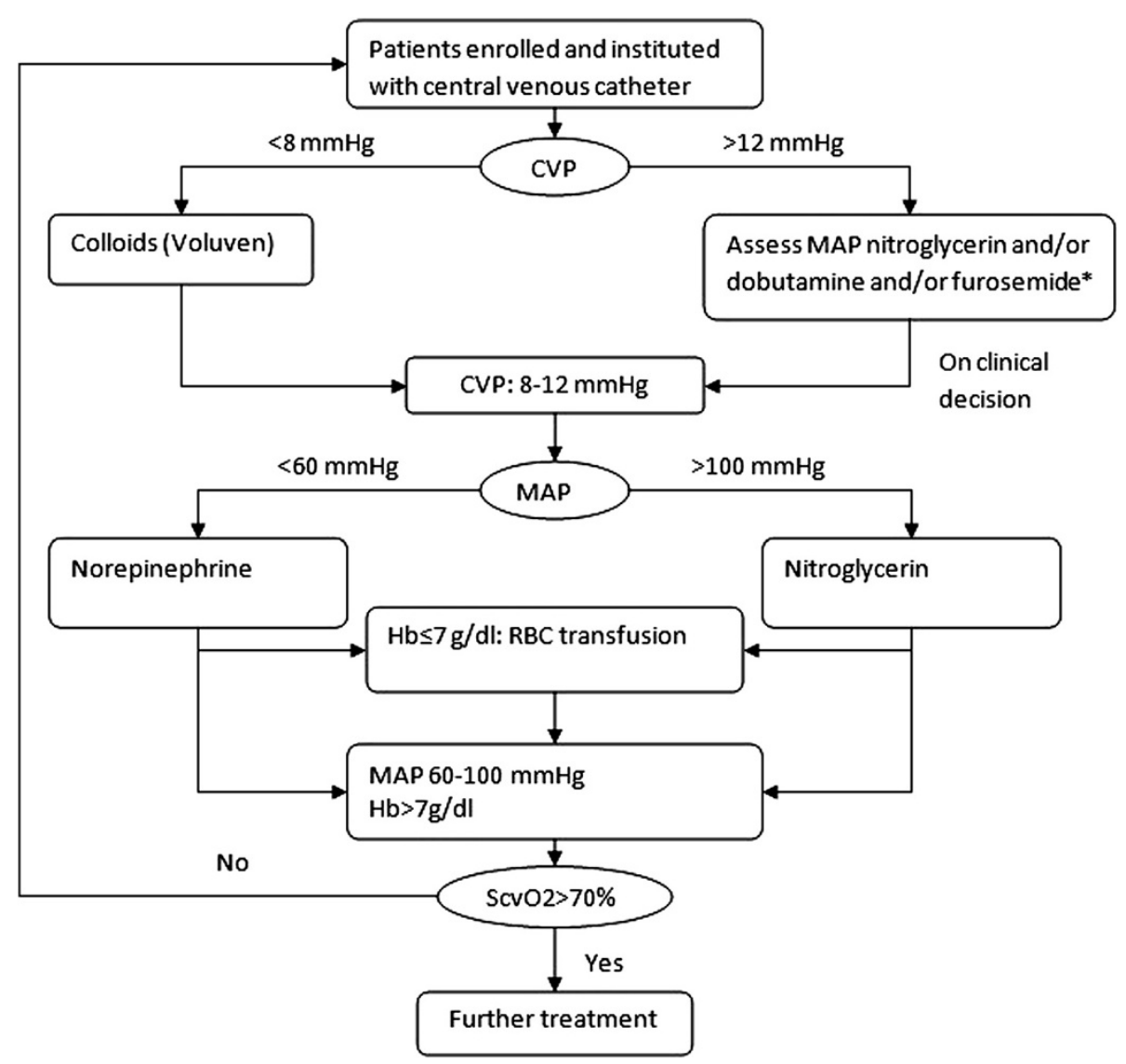

Figure 2 Algorithm for hemodynamic management in the control arm. If CVP $<8 \mathrm{mmHg}$, a $500 \mathrm{ml}$ bolus of hydroxyethyl starch 130/0.4 (Voluven ${ }^{\circledR}$ ) was infused over $30 \mathrm{~min}$ aiming at a CVP of 8 to $12 \mathrm{mmHg}$. The bolus can be repeated if the target is not reached. If CVP $>12 \mathrm{mmHg}$, furosemide and/or nitroglycerin and/or dobutamine are used at the discretion of the attending physician. If $\mathrm{MAP}<60 \mathrm{mmHg}$, norepinephrine is started at $0.05 \mu \mathrm{g} \cdot \mathrm{kg}^{-1} \cdot \mathrm{min}^{-1}$ with the option to increase at an increment of $0.05 \mu \mathrm{g} \cdot \mathrm{kg}^{-1} \cdot \mathrm{min}^{-1}$. If MAP $>100 \mathrm{mmHg}$, nitroglycerin is given at the dose range of 0.5 to $3.0 \mu \mathrm{g} \cdot \mathrm{kg}^{-1} \cdot \mathrm{min}^{-1}$. An RBC transfusion is triggered when $\mathrm{Hb}<7 \mathrm{~g} . \mathrm{dl}^{-1}$. $\mathrm{ScvO}_{2}$ is maintained $>70 \%$. CVP, central venous pressure; Hb, hemoglobin; $\mathrm{RBC}$, red blood cell; $\mathrm{SCvO}_{2}$, central venous oxygen saturation.

made to mask the study researchers and participants [30]. We use the same electrocardiogram (ECG) monitor (Philips IntelliVue Patient Monitor with a PiCCO module) for both intervention and control arms. A sham procedure of injecting cold water is performed for patients in the control arm. Investigators who collect baseline characteristics and follow-up participants are blinded to patient assignment.

\section{Ethical aspects}

The study has been approved by the ethics committees of Jinhua Municipal Central Hospital, the Traditional Chinese Medical Hospital of Jinhua City, Dongyang People's Hospital and the First People's Hospital of Yongkang City. The research will be explained in detail to the patient or the next-of-kin prior to enrollment. The explanation will include the type and method of the study, the complications of PiCCO monitoring and the potential benefit or harm of the intervention. Written informed consent will be obtained from the patients or their surrogates. The patient or surrogate can withdraw from the study at any time.

The study is conducted according to the Declaration of Helsinki.

\section{Discussion}

Fluid therapy is an art in the treatment of critically ill patients. To facilitate treatment and improve patient outcomes, every effort has been made to enhance the technology used for measuring relevant physiological parameters. These parameters allow us to better understand the underlying mechanisms of certain disorders. For instance, in septic shock, hemodynamic monitoring will typically present a low systemic vascular resistance and high or normal-high cardiac output. Intuitively, an understanding of pathophysiological mechanisms will eventually translate into improvements in clinical outcomes. Pulmonary artery catheters (PACs) have been 
widely used for several decades only because they allow clinicians to get more information regarding hemodynamic status, but without clinical evidence of improved outcomes. In response to this lack of evidence, several randomized controlled trials have been conducted to test the usefulness of PACs in improving clinical outcomes [31-33]. Unfortunately, all these trials consistently show that PACs do no better than controls regarding patient outcomes, but they increase medical costs significantly. These disappointing results have tempered the enthusiasm for PACs, and a survey showed that the use of PACs decreased by $65 \%$ during recent decades [34-36].

However, the failure of PACs in improving clinical outcomes does not mean that the measurement of hemodynamic parameters is useless. On the contrary, it reflects the limited understanding of the complex hemodynamic characteristics in critically ill patients. With the declining use of PACs, there is an increasing number of alternatives for hemodynamic monitoring. The PiCCO system is one such alternative, which integrates a wide series of both static and dynamic hemodynamic parameters through a combination of TPTD and pulse contour analysis. The PiCCO system has several advantages over a PAC. First, PiCCO is less invasive than a PAC, so that the severe complications attributable to PACs, such as a pulmonary embolism, pulmonary artery rupture and arrhythmia, are less likely to occur [37]. Furthermore, the arterial canalization required for PiCCO is safe and no significant adverse events for the usually used femoral site have been demonstrated $[38,39]$. Second, the PiCCO system has the unique ability to measure global end diastolic volume (GEDV) and EVLW. Multiple studies have demonstrated the superiority of GEDV over filling pressures (for example the central venous pressure and pulmonary artery wedge pressure) in estimating cardiac preload [40-42]. EVLWI is a quantitative assessment of pulmonary edema, which has been shown to be associated with clinical outcomes, and EVLW-directed fluid therapy may be potentially useful in improving patient clinical outcomes, such as the duration of mechanical ventilation, length of stay in ICU and mortality [43-45]. Third, PiCCO allows continuous measurement of cardiac output, which is potentially useful given the rapidly changing hemodynamic conditions in critically ill patients. Fourth, the PiCCO system is an 'all inclusive' hemodynamic monitor, which integrates an array of parameters. Adjusting fluid parameters by considering all aspects of cardiac performance may confer better clinical outcomes than using a single hemodynamic parameter [4]. However, compared with a PAC, the PiCCO device cannot monitor pulmonary artery (PA) pressure, pulmonary artery occlusion pressure (PAOP) and mixed venous oxygen saturation. Filling pressures, as previously mentioned, are not an accurate parameter of cardiac preload. Thus, PAOP measurements are not mandatory and can be replaced by GEDV to estimate cardiac preload. Furthermore, although not numerically exchangeable, mixed venous oxygen saturation can be approximated by central venous oxygenation saturation [46-48]. Therefore, based on current knowledge, the PiCCO system appears to be superior to the PAC in hemodynamic monitoring of critically ill patients.

The current study aims to investigate the usefulness of the PiCCO system in improving outcomes for patient with ARDS and septic shock. We believe that this randomized controlled trial will provide new evidence for fluid management in critical care settings.

\section{Trial status}

The trial is currently recruiting study subjects.

\section{Abbreviations}

ARDS: acute respiratory distress syndrome; Cl: cardiac output; CRBSI: catheterrelated bloodstream infection; CRRT: continuous renal replacement therapy; CVP: central venous pressure; ECG: electrocardiogram; EGDT: early goaldirected therapy; EVLW: extravascular lung water; EVLWI: extravascular lung water index; GEDV: global end diastolic volume; Hb: hemoglobin level; ITBVI: intrathoracic blood volume index; ITT: intention to treat; MAP: mean arterial pressure; PA: pulmonary artery; PAC: pulmonary artery catheter; PAOP: pulmonary artery occlusion pressure; PEEP: positive end-expiratory pressure; PiCCO: Pulse index Continuous Cardiac Output; RBC: red blood cell; SBP: systolic blood pressure; $\mathrm{S}_{\mathrm{CVO}_{2}}$ : central venous oxygen saturation; SOFA: sequential organ failure assessment; TPTD: transpulmonary thermodilution technique; WBC: white blood cell.

\section{Competing interests}

The authors declare that they have no competing interests. None of the authors received financial funds from Pulsion Medical Systems.

\section{Authors' contributions}

ZZ and XX contributed equally to this study and they coordinate, enrol and monitor the study subjects. HN has contributed to the study protocol. HF enrolls subjects and collects data. He is also responsible for monitoring safety. HC and ZZ contributed to the study protocol and they are responsible for the performance of PiCCO monitoring. MY contributed to the revision of the manuscript and acts as statistical consultant. All authors read and approved the final manuscript.

\section{Acknowledgments}

We are indebted to the nursing staff, especially Qiufang Tang and Lifei Pan for coordinating the performance of PiCCO monitoring.

\section{Author details}

'Department of Critical Care Medicine, Jinhua Municipal Central Hospital, 351 Mingyue Street, Jinhua City, Zhejiang 3210002, PR China. ${ }^{2}$ Department of Surgery, Limb Preservation and Wound Care Research, Boston Medical Center and Boston University School of Medicine, Boston, MA 02118, USA. ${ }^{3}$ Department of Critical Care Medicine, Traditional Chinese Medical Hospital of Jinhua City, Jinhua City, Zhejiang, PR China.

Received: 1 December 2012 Accepted: 21 January 2013

Published: 1 February 2013

\section{References}

1. Trof RJ, Beishuizen A, Cornet AD, de Wit RJ, Girbes AR, Groeneveld AB: Volume-limited versus pressure-limited hemodynamic management in septic and nonseptic shock. Crit Care Med 2012, 40(4):1177-1185. 
2. Boyd JH, Forbes J, Nakada TA, Walley KR, Russell JA: Fluid resuscitation in septic shock: a positive fluid balance and elevated central venous pressure are associated with increased mortality. Crit Care Med 2011, 39(2):259-265.

3. Harvey S, Young D, Brampton W, Cooper AB, Doig G, Sibbald W, Rowan K: Pulmonary artery catheters for adult patients in intensive care. Cochrane Database Syst Rev 2006, 19(3):CD003408.

4. Oren-Grinberg A: The PiCCO monitor. Int Anesthesiol Clin 2010, 48(1):57-85.

5. Broch O, Renner J, Gruenewald M, Meybohm P, Höcker J, Schöttler J, Steinfath M, Bein B: Variation of left ventricular outflow tract velocity and global end-diastolic volume index reliably predict fluid responsiveness in cardiac surgery patients. J Crit Care 2012, 27(3):325. e7-325.e13.

6. Zhang Z, Lu B, Sheng X, Jin N: Accuracy of stroke volume variation in predicting fluid responsiveness: a systematic review and meta-analysis. J Anesth 2011, 25(6):904-916.

7. MutohT KK, Ishikawa T, Terasaka S: Performance of bedside transpulmonary thermodilution monitoring for goal-directed hemodynamic management after subarachnoid hemorrhage. Stroke 2009, 40(7):2368-2374.

8. Goepfert MS, Richter PH, von Sandersleben A, Gruetzmacher J, Rafflenbeul E, Roeher K, ZuEulenburg C, ReichenspurnerH GAE, Reuter DA: Does early perioperative goal directed therapy using functional and volumetric hemodynamic parameters improve therapy in cardiac surgery? A prospective, randomized controlled trial. Intensive Care Med 2011, 37(1):S132-P 0506

9. Simmons RS, Berdine GG, Seidenfeld JJ, Prihoda TJ, Harris GD, Smith JD, Gilbert TJ, Mota E, Johanson WG Jr: Fluid balance and the adult respiratory distress syndrome. Am Rev Respir Dis. 1987, 135(4):924-929.

10. Phillips CR, Chesnutt MS, Smith SM: Extravascular lung water in sepsisassociated acute respiratory distress syndrome: indexing with predicted body weight improves correlation with severity of illness and survival. Crit Care Med 2008, 36(1):69-73.

11. Sakka SG, Klein M, Reinhart K, Meier-Hellmann A: Prognostic value of extravascular lung water in critically ill patients. Chest 2002, 122(6):2080-2086.

12. Zhang $\mathrm{Z}, \mathrm{Lu} \mathrm{B}, \mathrm{Ni} \mathrm{H}$ : Prognostic value of extravascular lung water index in critically ill patients: a systematic review of the literature. J Crit Care 2012, 27(4):420. e1-8.

13. Rivers E, Nguyen B, Havstad S, Ressler J, Muzzin A, Knoblich B, Peterson E, Tomlanovich M: Early goal-directed therapy in the treatment of severe sepsis and septic shock. N Engl J Med. 2001, 345(19):1368-1377.

14. O'Neill R, Morales J, Jule M: Early goal-directed therapy (EGDT) for severe sepsis/septic shock: which components of treatment are more difficult to implement in a community-based emergency department? J Emerg Med 2012, 42(5):503-510

15. Peake S, Webb S, Delaney A: Early goal-directed therapy of septic shock: we honestly remain skeptical. Crit Care Med 2007, 35(3):994-995

16. Dellinger RP, Levy MM, Carlet JM, Bion J, Parker MM, Jaeschke R, Reinhart K, Angus DC, Brun-Buisson C, Beale R, Calandra T, Dhainaut JF, Gerlach H Harvey M, Marini JJ, Marshall J, Ranieri M, Ramsay G, Sevransky J, Thompson BT, Townsend S, Vender JS, Zimmerman JL, Vincent JL: Surviving sepsis campaign: international guidelines for management of severe sepsis and septic shock: 2008. Crit Care Med 2008, 36(1):296-327.

17. Definition Task Force ARDS, Ranieri VM, Rubenfeld GD, Thompson BT, Ferguson ND, Caldwell E, Fan E, Camporota L, Slutsky AS: Acute respiratory distress syndrome: the Berlin definition. JAMA 2012, 307(23):2526-2533.

18. Heerdt PM, Pond CG, Blessios GA, Rosenbloom M: Inaccuracy of cardiac output by thermodilution during acute tricuspid regurgitation. Ann Thorac Surg 1992, 53(4):706-708.

19. Merrick SH, Hessel EA, Dillard DH: Determination of cardiac output by thermodilution during hypothermia. Am J Cardiol 1980, 46(3):419-422.

20. Giraud R, Siegenthaler N, Park C, Beutler S, Bendjelid K: Transpulmonary thermodilution curves for detection of shunt. Intensive Care Med 2010, 36(6):1083-1086

21. Segal E, Katzenelson R, Berkenstadt $H$, Perel A: Transpulmonarythermodilution cardiac output measurement using the axillary artery in critically ill patients. J ClinAnesth 2002, 14(3):210-213.

22. Monnet $X$, Persichini R, Ktari M, Jozwiak M, Richard C, Teboul JL: Precision of the transpulmonary thermodilution measurements. Crit Care 2011, 15(4):R204

23. Bendjelid $\mathrm{K}$ : When to recalibrate the PiCCO? From a physiological point of view, the answer is simple. Acta Anaesthesiol Scand 2009, 53(5):689-690.
24. Heise D, Faulstich M, Mörer O, Bräuer A, Quintel M: Influence of continuous renal replacement therapy on cardiac output measurement using thermodilution techniques. Minerva Anestesiol 2012, 78(3):315-321.

25. Dufour N, Delville M, Teboul J-L, Camous L, Favierdu Noyer A, Richard C, Monnet $X$ : Transpulmonary thermodilution measurements are not affected by continuous veno-venous hemofiltration at high blood pump flow. Intensive Care Med 2012, 38(7):1162-1168

26. Goepfert MS, Reuter DA, Akyol D, Lamm P, Kilger E, Goetz AE: Goal-directed fluid management reduces vasopressor and catecholamine use in cardiac surgery patients. Intensive Care Med 2007, 33(1):96-103.

27. Lenkin Al, Kirov MY, Kuzkov W, Paromov KV, Smetkin AA, Lie M, Bjertnæs L: Comparison of goal-directed hemodynamic optimization using pulmonary artery catheter and transpulmonary thermodilution in combined valve repair: a randomized clinical trial. Crit Care Res Pract 2012, Epub.

28. Rivers E, Nguyen B, Havstad S, Ressler J, Muzzin A, Knoblich B, Peterson E, Tomlanovich M, Early Goal-Directed Therapy Collaborative Group: Early goal-directed therapy in the treatment of severe sepsis and septic shock. N Engl J Med 2001, 345(19):1368-1377.

29. ZambonM VJL: Mortality rates for patients with acute lung injury/ARDS have decreased over time. Chest 2008, 133(5):1120-1127.

30. Boutron I, Guittet L, Estellat C, Moher D, Hróbjartsson A, Ravaud P: Reporting methods of blinding in randomized trials assessing nonpharmacological treatments. PLoS Med 2007, 4(2):e61.

31. Rhodes A, Cusack RJ, Newman PJ, Grounds RM, Bennett ED: A randomised, controlled trial of the pulmonary artery catheter in critically ill patients. Intensive Care Med 2002, 28(3):256-264.

32. Harvey S, Harrison DA, Singer M, Ashcroft J, Jones CM, Elbourne D, Brampton W, Williams D, Young D, Rowan K: PAC-man study collaboration. Assessment of the clinical effectiveness of pulmonary artery catheters in management of patients in intensive care (PAC-Man): a randomised controlled trial. Lancet 2005, 366(9484):472-477.

33. Sandham JD, Hull RD, Brant RF, Knox L, Pineo GF, Doig CJ, Laporta DP, Viner S, Passerini L, Devitt H, Kirby A, Jacka M: A randomized, controlled trial of the use of pulmonary-artery catheters in high-risk surgical patients. N Engl J Med 2003, 348(1):5-14

34. Wiener RS, Welch HG: Trends in the use of the pulmonary artery catheter in the United States, 1993-2004. JAMA 2007, 298(4):423-429.

35. Koo KK, Sun JC, Zhou Q, Guyatt G, Cook DJ, Walter SD, Meade MO Pulmonary artery catheters: evolving rates and reasons for use. Crit Care Med 2011, 39(7):1613-1618.

36. Cowie BS: Does the pulmonary artery catheter still have a role in the perioperative period. Anaesth Intensive Care 2011, 39(3):345-355.

37. Wheeler AP, Bernard GR, Thompson BT, Schoenfeld D, Wiedemann HP DeBoisblanc B, Connors AF Jr, Hite RD, Harabin AL: Pulmonary-artery versus central venous catheter to guide treatment of acute lung injury. N Engl J Med 2006, 354(21):2213-2224.

38. Cousins TR, O'Donnell JM: Arterial cannulation: a critical review. AANAJ 2004, 72(4):267-271.

39. ScheerB PA, Pfeiffer UJ: Clinical review: complications and risk factors of peripheral arterial catheters used for haemodynamic monitoring in anaesthesia and intensive care medicine. Crit Care 2002, 6(3):199-204.

40. Michard F, Alaya S, Zarka V, Bahloul M, Richard C, Teboul JL: Global enddiastolic volume as an indicator of cardiac preload in patients with septic shock. Chest 2003, 124(5):1900-1908.

41. Sakka SG, Rühl CC, Pfeiffer UJ, Beale R, McLuckie A, Reinhart K, MeierHellmann A: Assessment of cardiac preload and extravascular lung water by single transpulmonary thermodilution. Intensive Care Med 2000, 26(2):180-187.

42. Trof RJ, Danad I, Reilingh MW, Breukers RM, Groeneveld AB: Cardiac filling volumes versus pressures for predicting fluid responsiveness after cardiovascular surgery: the role of systolic cardiac function. Crit Care 2011, 15(1):R73

43. Bognar Z, Foldi V, Rezman B, Bogar L, Csontos C: Extravascular lung water index as a sign of developing sepsis in burns. Burns 2010, 36(8):1263-1270.

44. Chung FT, Lin SM, Lin SY, LinH C: Impact of extravascular lung water index on outcomes of severe sepsis patients in a medical intensive care unit. RespirMed 2008, 102(7):956-961.

45. Davey-Quinn A, Gedney JA, Whiteley SM, Bellamy MC: Extravascular lung water and acute respiratory distress syndrome-oxygenation and outcome. Anaesth Intensive Care 1999, 27(4):357-362. 
46. Alshaer A, Abdel-Meguid ME, Ibraheim O, Fawzi K, Abdulsalam I, Sheta S, Abdullah KM, El-Demerdash A, Al-Satli R, Abdelall M, Bakir BM, Alnahal N Abdulrahman $Y$, Alhamoud $H$ : Mixed venous versus central venous oxygen saturation in patients undergoing on pump beating coronary artery bypass grafting. Saudi J Anaesth 2010, 4(2):63-67.

47. Dahmani S, Paugam-Burtz C, Gauss T, Alves M, Le Bihan E, Necib S, Belghiti J, Mantz J: Comparison of central and mixed venous saturation during liver transplantation in cirrhotic patients: a pilot study. Eur J Anaesthesiol 2010, 27(8):714-719.

48. Shepherd SJ, Pearse RM: Role of central and mixed venous oxygen saturation measurement in perioperative care. Anesthesiology 2009, 111(3):649-656.

doi:10.1186/1745-6215-14-32

Cite this article as: Zhang et al:: Use of the PiCCO system in critically ill patients with septic shock and acute respiratory distress syndrome: a study protocol for a randomized controlled trial. Trials 2013 14:32.

\section{Submit your next manuscript to BioMed Central and take full advantage of:}

- Convenient online submission

- Thorough peer review

- No space constraints or color figure charges

- Immediate publication on acceptance

- Inclusion in PubMed, CAS, Scopus and Google Scholar

- Research which is freely available for redistribution 